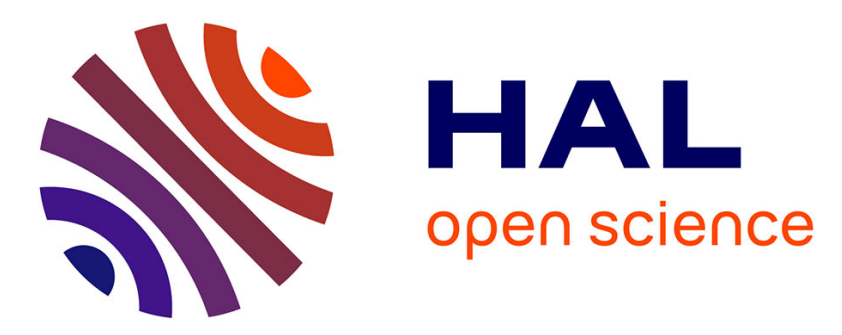

\title{
High energy heavy-ion irradiation effects in Metglas 2 705 MN Co 72Fe6Mo2Si5B15
}

\author{
R. Stephan, J. Provost, A. Maignan, J. Dural, D. Groult, J.C. Jousset, B.
}

Raveau

\section{- To cite this version:}

R. Stephan, J. Provost, A. Maignan, J. Dural, D. Groult, et al.. High energy heavy-ion irradiation effects in Metglas 2705 MN Co 72Fe6Mo2Si5B15. Revue de Physique Appliquée, 1988, 23 (5), pp.873878. 10.1051/rphysap:01988002305087300 . jpa-00245890

\section{HAL Id: jpa-00245890 https://hal.science/jpa-00245890}

Submitted on 1 Jan 1988

HAL is a multi-disciplinary open access archive for the deposit and dissemination of scientific research documents, whether they are published or not. The documents may come from teaching and research institutions in France or abroad, or from public or private research centers.
L'archive ouverte pluridisciplinaire HAL, est destinée au dépôt et à la diffusion de documents scientifiques de niveau recherche, publiés ou non, émanant des établissements d'enseignement et de recherche français ou étrangers, des laboratoires publics ou privés. 
Classification

Physics Abstracts

$61.80 \mathrm{~J}-61.40 \mathrm{D}$

\title{
High energy heavy-ion irradiation effects in Metglas $2705 \mathrm{MN}$ $\mathrm{Co}_{72} \mathrm{Fe}_{6} \mathrm{Mo}_{2} \mathrm{Si}_{5} \mathbf{B}_{15}$
}

\author{
R. Stephan (*), J. Provost, A. Maignan, J. Dural $\left({ }^{1}\right)$, D. Groult, J. C. Jousset $\left({ }^{1}\right)$ and B. Raveau \\ Laboratoire de Cristallographie et Sciences des Matériaux (CRISMAT), ISMRa, Bd du Maréchal Juin, \\ 14032 Caen Cedex, France \\ ( ${ }^{1}$ CIRIL, Bd Henri Becquerel, B.P. 5133, 14032 Caen Cedex, France
}

(Reçu le 21 septembre 1987, révisé le 18 décembre 1987, accepté le 12 janvier 1988)

\begin{abstract}
Résumé. - L'alliage amorphe $\mathrm{Co}_{72} \mathrm{Fe}_{6} \mathrm{Mo}_{2} \mathrm{Si}_{5} \mathrm{~B}_{15}$ d'appellation commerciale $2705 \mathrm{MN}$ a été irradié à $77 \mathrm{~K}$ par des ions krypton de 2,6 GeV par ion. Les cycles d'hystérésis d'échantillons toroïdaux empilés perpendiculairement au faisceau d'ions ont été enregistrés in situ pour des fluences comprises entre $5 \times 10^{11}$ et $1,2 \times 10^{13} \mathrm{Kr} \mathrm{cm}^{-2}$. Ils témoignent d'une diminution de la perméabilité initiale et d'un accroissement de l'induction rémanente et du champ coercitif avec la dose d'irradiation. Ces effets pourraient correspondre à une mise en ordre directionnel à courte distance induite par les défauts produits par chocs élastiques.
\end{abstract}

Abstract. - The amorphous alloy $\mathrm{Co}_{72} \mathrm{Fe}_{6} \mathrm{Mo}_{2} \mathrm{Si}_{5} \mathrm{~B}_{15}$, Metglas $2705 \mathrm{MN}$, has been irradiated at $77 \mathrm{~K}$ by 2.6 GeV-Kr ions. The hysteresis loops of toroidal samples piled up normally to the ion-beam have been registered in situ for fluences ranging from $5 \times 10^{11}$ to $1.2 \times 10^{13} \mathrm{~cm}^{-2}$. Decrease in permeability and increases in remanence and coercive force are thought to be due to short range ordering process enhanced by excess of induced vacancy-like defects.

\section{Introduction.}

The magnetic properties of soft ferromagnets can be greatly influenced by thermal treatment of magnetic annealing. This effect is usually interpreted with the Néel-Chikazumi model [1, 2, 3, 4]. In magnetic annealing, as atomic mobility is thermaly enhanced, some pairs of neighbors like atoms can be aligned in the magnetization direction. It is also well known that atomic mobility can be stimulated by irradiation. Some consistant work [5] has been done in that field of irradiation-induced magnetic annealing which shows that irradiation of crystalline alloys exhibits significant change of their magnetic properties. Few investigations have been performed on amorphous magnetic alloys.

In this paper we report on a heavy ion irradiation experiment on Metglas $2705 \mathrm{MN}$ amorphous alloy. During the irradiation the hysteresis loop was re-

Experiment performed at National Laboratory G.A.N.I.L., Caen, France.

(*) Present address: Thomson-Sintra, Activités sousmarines, Groupe Mines, Magnétisme-Optique, 29601 Brest Cedex, France. corded and the initial permeability was measured, both with a sinusoidal excitation field at $2 \mathrm{kHz}$ frequency. Samples were irradiated at the Grand Accélérateur National d'Ions Lourds (G.A.N.I.L., Caen) with $\mathrm{Kr}$ ions having an energy per nucleon of $31 \mathrm{MeV} / \mathrm{A}$ i.e. $2.6 \mathrm{GeV}$ per ion.

\section{Experimental procedure.}

SAMPLES. - The atomic composition of Metglas $2705 \mathrm{MN}$ is :

$$
\text { Co } 72 \% \text {; Fe } 6 \% \text {; B } 15 \% \text {; Si } 5 \% \text {; Mo } 2 \% \text {. }
$$

The alloy was supplied by Allied Chemical as ribbons, $15 \mu \mathrm{m}$ thick, $25 \mathrm{~mm}$ wide. Using chemical cutting, the strip was cut out in the form of pseudotoroids (Fig. 1). The outer diameter was of $15 \mathrm{~mm}$ and the inner diameter of $10 \mathrm{~mm}$. The extra rectangular part of the pseudo-toroid allows to cool down the sample by soldering it on a $77 \mathrm{~K}$ copper sample holder.

Typical values given by Metglas data sheet are :

Saturation field $B_{\mathrm{s}}=1.2 \mathrm{~T}$

Magnetostrictive coefficient $\lambda_{\mathrm{s}}=0$ 
Curie temperature $T_{\mathrm{C}}=680 \mathrm{~K}$

Crystallization temperature $T_{\mathrm{x}}=803 \mathrm{~K}$

Density $d=8.0 \mathrm{~g} / \mathrm{cm}^{3}$

Coercitive force $H_{\mathrm{c}}(\mathrm{d}$. c ) $=5.2 \mathrm{~A} / \mathrm{m}$

Remanent field $B_{\mathrm{r}}=0.77 \mathrm{~T}$.
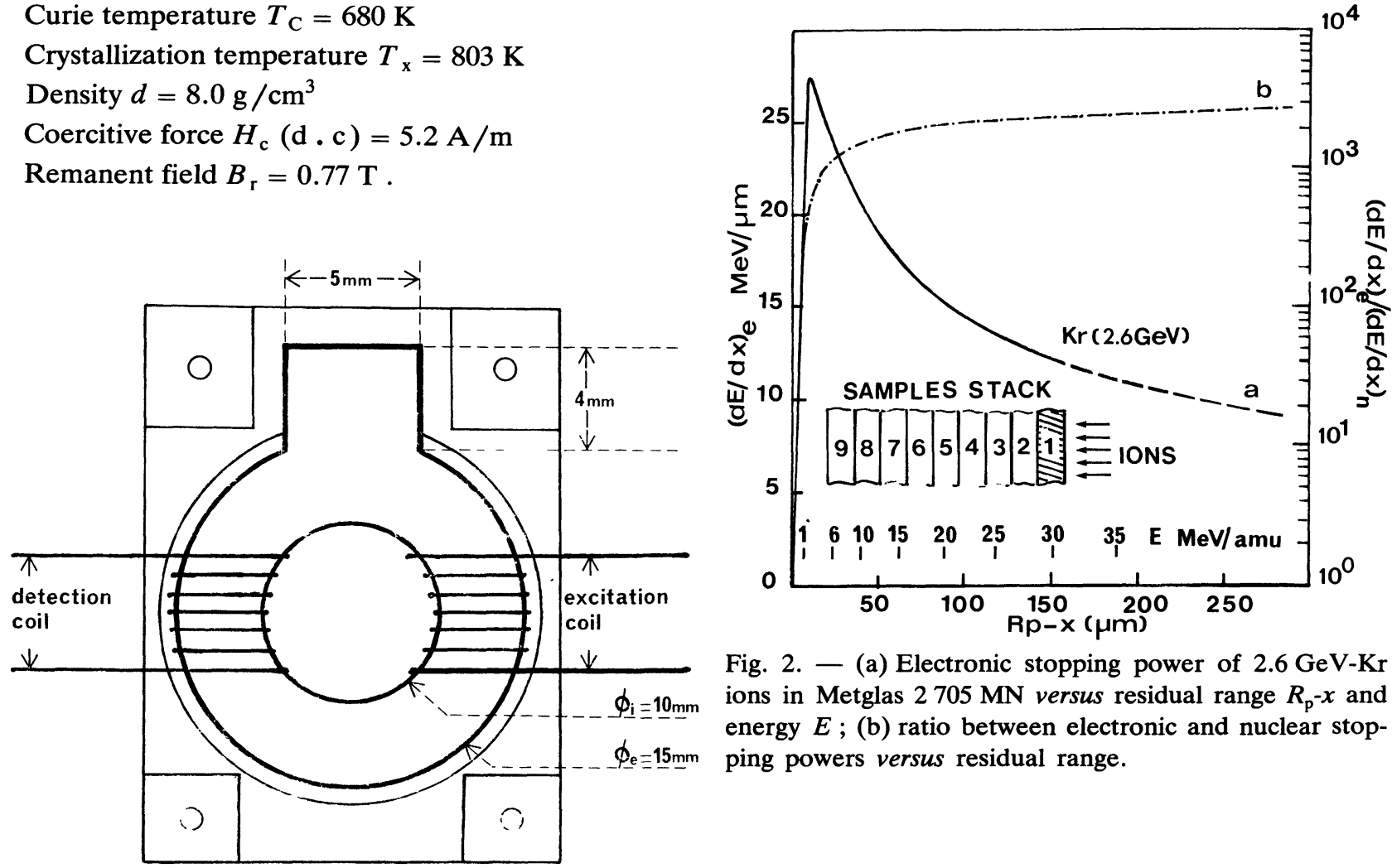

Fig. 2. - (a) Electronic stopping power of $2.6 \mathrm{GeV}-\mathrm{Kr}$ ions in Metglas $2705 \mathrm{MN}$ versus residual range $R_{\mathrm{p}}-x$ and energy $E$; (b) ratio between electronic and nuclear stopping powers versus residual range.

Fig. 1. - Schematic drawing of pseudo-toroidal sample fixed on I.R.A.B.A.T. tail.

EXPERIMENTAL. - The samples were irradiated in the $77 \mathrm{~K}$ irradiation facility (IRABAT) of CIRIL [6]. The copper sample holder of the pseudo-toroids were piled up and fixed on the 77 K-IRABAT-tail. The sample holders were also cooled by helium gas in thermal contact with $77 \mathrm{~K}$-IRABAT-tail. The sample temperature during irradiation was recorded by means of thermocouples glued on samples and found ranging from $80 \mathrm{~K}$ to $110 \mathrm{~K}$.

Nine pseudo-toroids were piled up normally to the ion beam, the thickness of the stack being thus lower than the mean value of the projected range $\left(R_{\mathrm{p}}=157 \pm 1 \mu \mathrm{m}\right)$ calculated from Hubert's and Northcliffe's table (7-8) as shown in figure 2. The samples were numbered from 1 to 9 with respect to the entrance of the ion beam, the incoming energy ranging from $2.6 \mathrm{GeV}$ for sample 1 to $0.8 \mathrm{GeV}$ for sample 9.

Six of these samples corresponding to $\mathrm{n}^{\mathrm{os}} 1,5,6$, $7,8,9$ where choosen for hysteresis loop recording and initial permeability measurement by means of excitation and detection coils wounded directly on each sample using a thin copper wire. Winding was realized in order to minimize shadow effect of one coil on the following ones.

The irradiation sequences during our experiment were $20 \mathrm{~s}$ of irradiation with krypton ions followed by $180 \mathrm{~s}$ without ion beam. During the irradiation

time (20 s) the samples were in a demagnetized state. The following $180 \mathrm{~s}$ corresponding to the beam stops were used to measure initial permeability and hysteresis loops of the six samples. This time was also used to have the sample demagnetized prior the following $20 \mathrm{~s}$ of irradiation. The 200 seconds period of $2 \mathrm{kHz}$ current amplitude applied to the primary winding is shown in figure 3 . The average ion flux during irradiation was $4 \times 10^{9} \mathrm{~cm}^{-2} \cdot \mathrm{s}^{-1}$.

A function generator delivered a constant level output sinusoidal voltage at $2 \mathrm{kHz}$ frequency. This signal was applied to a 8 bits A/D converter working as a variable $G$ gain amplifier $(0<G<1)$. The primary coils were fed by the output of a power amplifier (Fig. 4).

The amplitude variation cycle of the primary excitation current shown in figure 3 is commanded by a microcomputer. The cycle start is synchronized with the signal delivered by G.A.N.I.L. when the ion beam stops in the experimental area. The delay time $t_{\mathrm{a}}$ (Fig. 3) is easily modified by soft ; $t_{\mathrm{a}}$ has been adjusted to be greater than the time constant of the sample temperature decay after the $20 \mathrm{~s}$ of irradiation by $\mathrm{Kr}$ ions. Thus, both measurements of initial permeability and hysteresis loop were performed at equilibrium temperature close to $77 \mathrm{~K}$.

The six secondary coils were connected to six analogic integrators. The integrated signals were digitalized and stored in the system memory. Voltage across a resistor $\left(R_{\mathrm{s}}\right.$ in Fig. 4$)$ in series, with the primary coil was also digitalized and stored. It was then easy to plot $B$ versus time, $B(t), H$ versus time $H(t)$ or $B$ versus $H, B(H)$ hysteresis loop. 


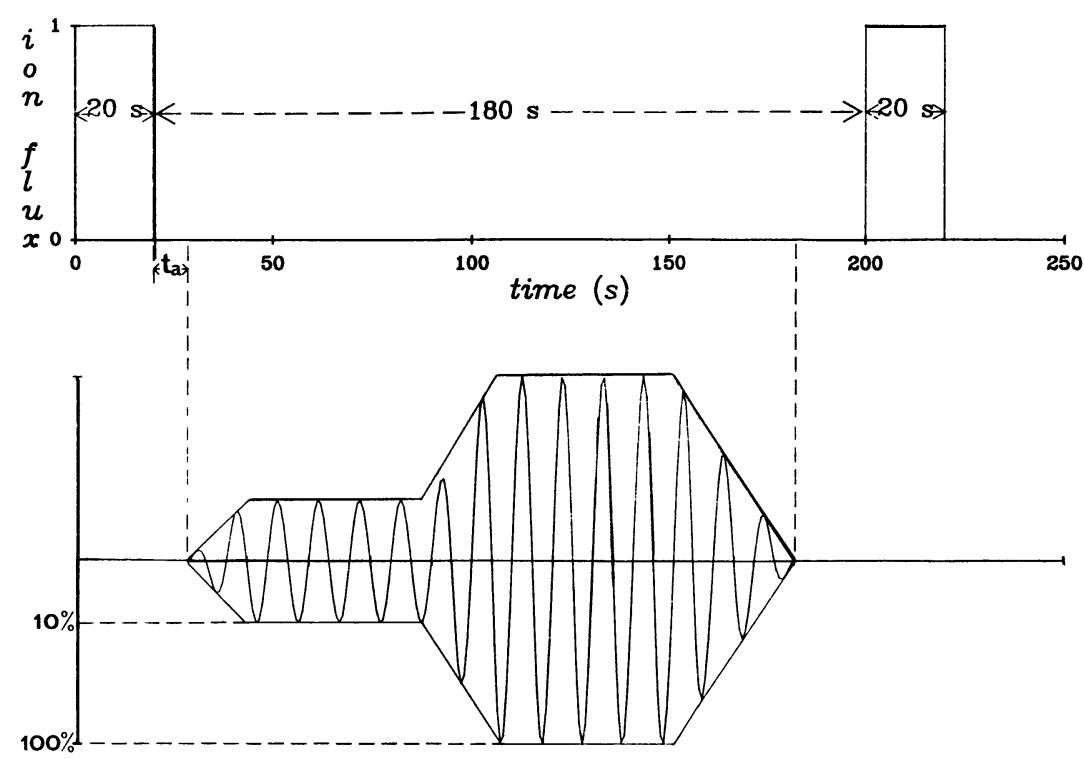

Fig. 3. - Irradiation and measurement sequences used for the registration of the hysteresis loops.

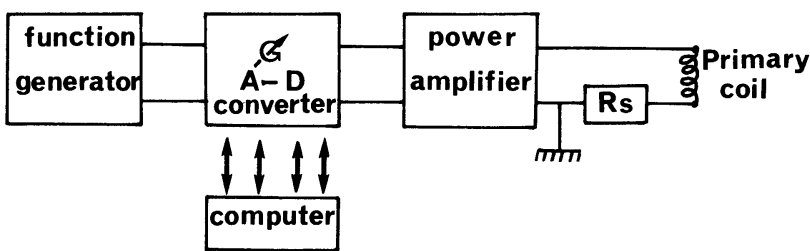

Fig. 4. - Automation scheme used for the registration of the hysteresis loops after irradiation and for the demagnetization of the samples before irradiation.

\section{Results.}

Typical hysteresis loops before and after irradiation are shown in figure 5. The initial permeability $\mu_{i}$ is measured from the slope of the dashed line in figure 5a. This recording was performed with a sinusoidal excitation field of amplitude $300 \mathrm{~A} / \mathrm{m}$ at $2 \mathrm{kHz}$ frequency. The excitation field amplitude used for the recording of low excitation field hysteresis loop $(30 \mathrm{~A} / \mathrm{m})$ was not idealy low for the
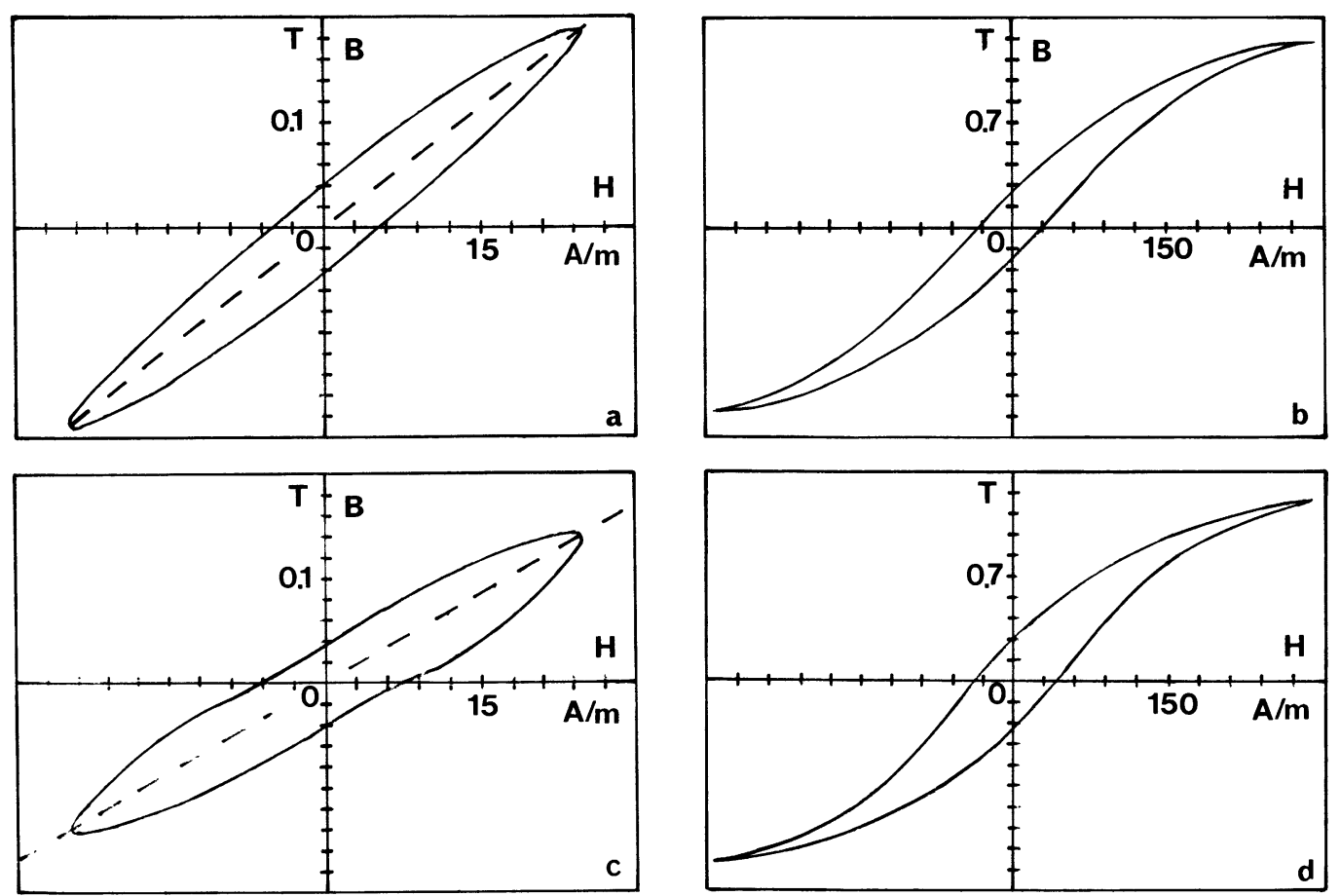

Fig. 5. - Typical hysteresis loops registered before and after irradiation by $2.6 \mathrm{GeV}-\mathrm{Kr}$ ions : (a) low excitation field before irradiation; (b) saturation excitation field before irradiation; (c) low excitation field after irradiation; (d) saturation excitation field after irradiation. 
$\mu_{i}$ measurement. It was not possible here to use a much lower excitation field due to the resolution of the A/D converter and measurement set up.

The relative variation $\Delta \mu_{\mathrm{i}} / \mu_{\mathrm{i} 0}$ of the initial permeability is plotted versus the ion fluence $\phi t$ in figure 6. $\mu_{\mathrm{i} 0}$ is the initial permeability before irradiation $(\phi t=0)$. The reduced remanent field $\Delta B_{\mathrm{r}} / B_{\mathrm{r} 0}$ and the reduced coercive force $\Delta H_{\mathrm{c}} / H_{\mathrm{c} 0}$ are plotted versus $\phi t$ in figure 7 and figure 8 .

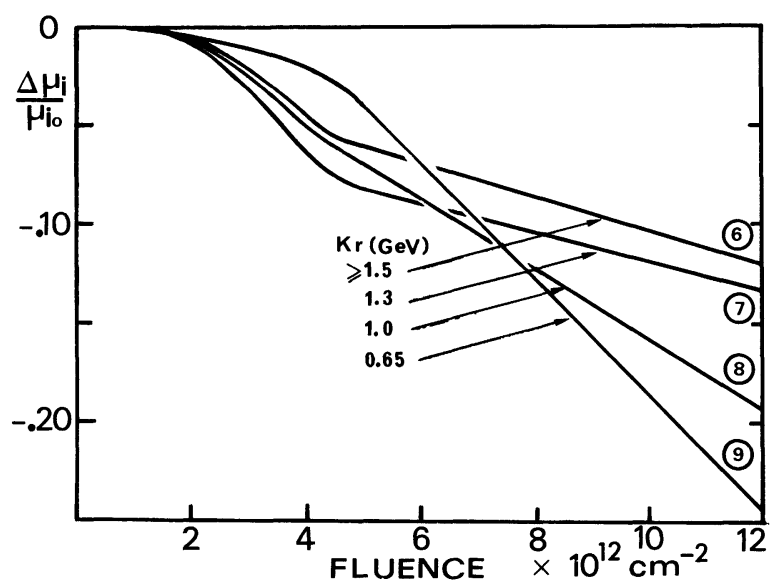

Fig. 6. - Decay of the relative permeability versus fluence for $2.6 \mathrm{GeV}-\mathrm{Kr}$ ions irradiated Metglas $2705 \mathrm{MN}$. Numbers in circles are relative to the place of the sample in the stack.

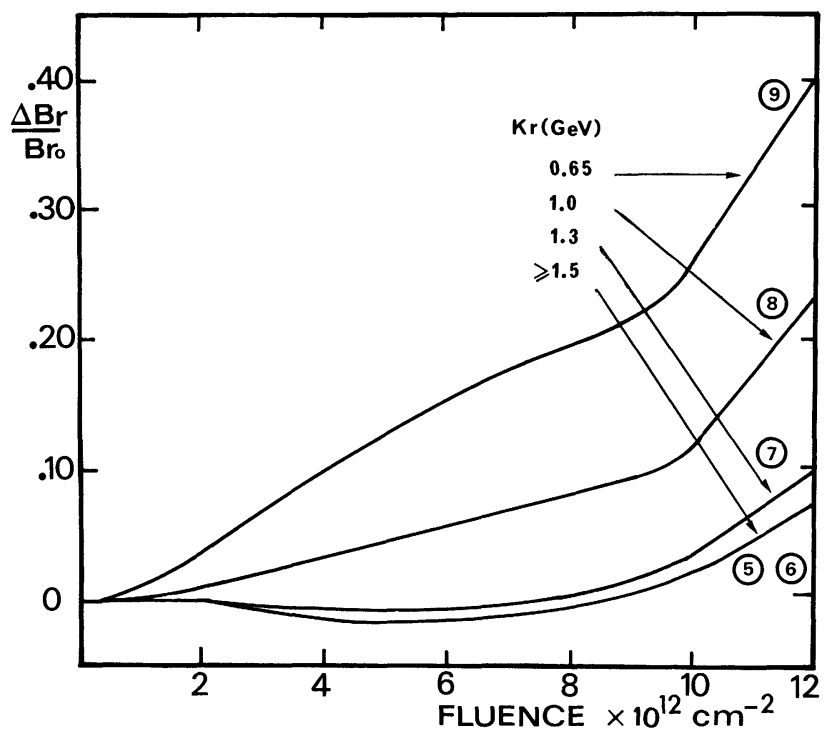

Fig. 7. - Change in remanence versus fluence for 2.6 GeV-Kr irradiation of Metglas $2705 \mathrm{MN}$.

\section{Discussion.}

Although the mechanisms responsible for the magnetic changes induced by irradiation in crystalline and amorphous soft magnetic alloys are not still well established, it has been suggested [9-10] that directional short range ordering based on Neel's theory

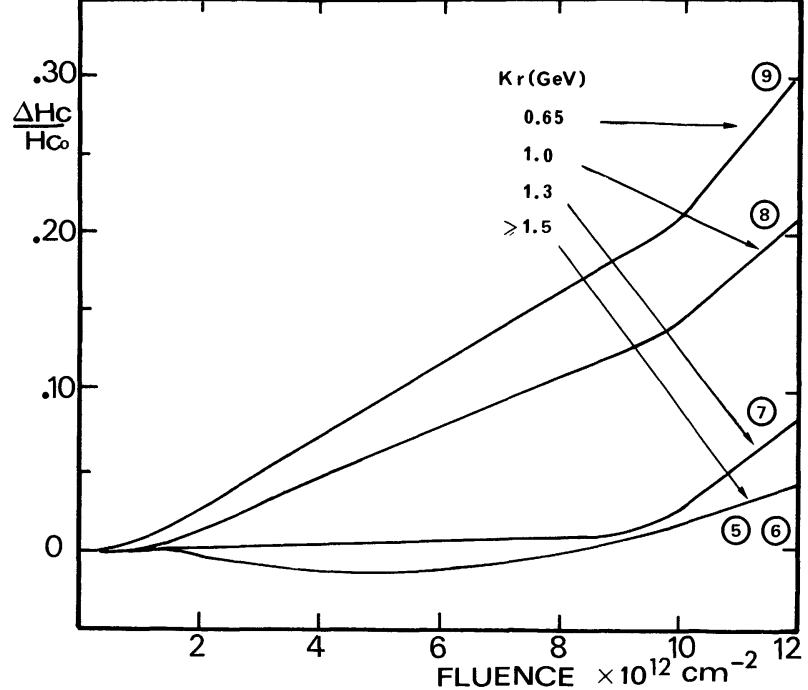

Fig. 8. - Change in coercive force versus fluence for 2.6 GeV-Kr irradiation of Metglas $2705 \mathrm{MN}$.

[1] and generation of pinning centers for domain walls would have a significant effect in decreasing permeability and increasing remanence and coercive force.

Both effects have thus been considered by Brown et al. [11] to explain the radiation damage produced by fast neutron $(E>0.1 \mathrm{MeV})$ bombardment in Metglas $2605 \mathrm{~S}$ and mumetal. On the other hand, Donnelly et al. [12] conclude that the effects induced in amorphous Fe-Ni-P-B alloys by $1.25 \mathrm{MeV}$-electron and $2.25 \mathrm{MeV}$ proton irradiations are probably not caused by the elastic collisions but like in annealing experiments, rather associated with the structural relaxation induced by the transient energy deposited by the incident particles.

In the case of highly energetic heavy ions $(>1 \mathrm{GeV})$, transient deposition of energy by inelastic collisions is particularly important as it can be seen in figure $2 \mathrm{a}$ which shows the electronic stopping power of $2.6 \mathrm{GeV}-\mathrm{Kr}$ ions in Metglas $2705 \mathrm{MN}$ as a function of the ion residual range and energy. It is worth noticing from figure $2 \mathrm{a}$ that the energy deposited by electronic stopping is about 4 orders of magnitude higher for $2.6 \mathrm{GeV}-\mathrm{Kr}$ ions than for 1.25 MeV-electrons. As a result, the enhancement of the radiation damage by electronic energy loss can be expected in Metglas $2705 \mathrm{MN}$, despite its metallic character, as it has been recently reported in Metglas $\mathrm{Fe}_{85} \mathrm{~B}_{15}$ [13]. Moreover, except in the stopping ion zone, the electronic energy loss is 2000 times higher than the nuclear energy loss (Fig. 2b). It can thus be expected that the effect assumed by Donnelly et al. [12] of the transient energy deposited by inelastic collisions should be greatly enhanced.

Attempting to distinguish electronic collision effects from that induced by elastic collisions only we have considered the relative changes of remanence, 
coercive force and permeability per elastic displacement per atom (dpa). The number of dpa has been calculated using the LSS theory [14] according to :

$$
\mathrm{dpa}=\phi t \int_{T_{\mathrm{d}}}^{T_{\mathrm{m}}} N_{\mathrm{d}(\mathrm{T})} \mathrm{d} \sigma(E, T)
$$

where $\mathrm{d} \sigma(E, T)$ is the differential cross section for an energy transfer $T$ between the incoming ion of energy $E$ and the primary knock-on atom (PKO) which received the energy $T . T_{\mathrm{d}}$ is the displacement threshold and $T_{\mathrm{m}}$ the maximum transferred energy. $N_{\mathrm{d}}(T)$ corresponds to the number of displacements created by a PKO of energy $T$; it has been estimated from Norgett et al. procedure [15].
However, as it can be observed on figures 6-7 and 8 , the results show a nearly linear variation of the magnetic properties against fluence above a critical value of $\phi t$ i.e. $\phi t \geqslant 10^{13} \mathrm{~cm}^{-2}$ whatever the place of the sample is in the stack (Fig. 2). Under such a fluence the results are indeed much more uncertain, especially for samples 6 to 1 located in the low electronic energy zone than for samples 7-8-9 which correspond to highest values of the electronic stopping power. Accordingly the calculations of the relative variations of $H_{\mathrm{c}} / H_{\mathrm{c} 0}, B_{\mathrm{r}} / B_{\mathrm{r} 0}$ and $\mu_{\mathrm{i}} / \mu_{\mathrm{i} 0}$ per dpa have been performed for $\phi t \geqslant 10^{13} \mathrm{~cm}^{-2}$. Their values are given in table I together with the position of the sample i.e. the mean value of the energy lost by electronic stopping. From this table it may be

Table I. - Relative variation of the magnetic properties per elastic displacement per atom (dpa) $\left(\phi t \geqslant 10^{13} \mathrm{~cm}^{-2}\right)$.

\begin{tabular}{|c|c|c|c|c|}
\hline Sample $\mathrm{N}^{\circ}$ & $\begin{array}{c}(-\mathrm{d} E / \mathrm{d} x)_{\mathrm{e}} \\
\mathrm{MeV} / \mu \mathrm{m}\end{array}$ & $\begin{array}{c}\left(\Delta H_{\mathrm{c}} / H_{\mathrm{c}_{0}}\right) / \mathrm{dpa} \\
\mathrm{dpa}^{-1}\end{array}$ & $\begin{array}{c}\left(\Delta B_{\mathrm{r}} / B_{\mathrm{r}_{0}}\right) / \mathrm{dpa} \\
\mathrm{dpa}^{-1}\end{array}$ & $\begin{array}{c}-\left(\Delta \mu_{\mathrm{i}} / \mu_{\mathrm{i} 0}\right) / \mathrm{dpa} \\
\mathrm{dpa}^{-1}\end{array}$ \\
\hline 9 & $22.8 \pm 1.6$ & $3200 \pm 200$ & $4600 \pm 300$ & $1600 \pm 100$ \\
8 & $20.1 \pm 1.1$ & $3250 \pm 150$ & $5000 \pm 200$ & $1600 \pm 100$ \\
7 & $18.1 \pm 1.0$ & $3700 \pm 300$ & $4700 \pm 300$ & $1500 \pm 50$ \\
6 & $16.4 \pm 0.6$ & $3800 \pm 400$ & $5300 \pm 500$ & $1500 \pm 100$ \\
\hline
\end{tabular}

concluded that defect production in Metglas $2705 \mathrm{MN}$ is mainly due to elastic collisions with the host atoms despite the high value of the electronic stopping power. Compared to electron irradiation effects in Fe-B and Fe-Ni-P-B amorphous alloys [1617] one can suggest that $2.6 \mathrm{GeV}-\mathrm{Kr}$ irradiation at $77 \mathrm{~K}$ induce similar vacancy-like defects which enhance the mobility of the surrounding atoms and then favor occurrence of short range ordering process [1-4].

\section{Conclusion.}

Contrary to recent experiments carried out at G.A.N.I.L. in Fe-B amorphous alloys [13] it may be assumed that $2.6 \mathrm{GeV}-\mathrm{Kr}$ ions correspond in amorphous $\mathrm{Co}_{72} \mathrm{Fe}_{6} \mathrm{Mo}_{2} \mathrm{Si}_{5} \mathrm{~B}_{15}$ to a zone of electronic energy loss lower or close to the threshold value which involves a change in the damage creation behavior. As a consequence, it would be of interest to perform irradiations with heavy ions having a specific energy loss higher than that of $2.6 \mathrm{GeV}-\mathrm{Kr}$ ions e.g. xenon ions to see if the relative changes of permeability, remanence and coercive force stand above that of $2.6 \mathrm{GeV}-\mathrm{Kr}$ ions.

\section{Acknowledgements.}

The authors are indebted to DRET contract $\mathrm{N}^{\circ}$ 86/1182/DRET 03 and to the Etablissement Public Régional de Basse Normandie for the financial support of this work. They are also grateful to referees for enlightening criticisms and suggestions.

\section{References}

[1] Neel, L., C. R. Hebd. Séan. Acad. Sci. 237 (1953) 1613 ; J. Phys. Rad. 15 (1954) 225.

[2] Tanaguchi, S. and Yamatomo, M., Sci. Rep. (Res. Inst. Tohoku University) A6 (1954) 330 ; A7 (1955) 269 ; A8 (1956) 173.

[3] Chikazumi, S. and Oomura, T., J. Phys. Soc. Jpn 10 (1955) 842.
[4] Chikazumi, S., Physics of Magnetism, Eds. John Wiley and Sons (Inc. New York) 1964 p. 369.

[5] Sery, R. S. and Gordon, D. I., J. Appl. Phys. 35 (1964) 879 ; Ibid. 36 (1965) 1221.

[6] Jousset, J. C., Ann. Chim. 9 (1984) 373.

[7] Hubert, F., Fleury, A., Bimbot, R. and Gardes, D., Ann. Phys. Fr. Suppl. Ser. 1 (1980). 
[8] Northcliffe, L. C. and Schilling, R. F., Nucl. Data Tables 7 (1970) 233.

[9] Schindler, A. I., Kernohan, R. H. and WeERTMAN, J., J. Appl. Phys. 35 (1964) 2640.

[10] Stephen, J., Nucl. Energy 76 (1969).

[11] Brown, R. D., Cost, J. R. and Stanley, J. T., J. Nucl. Mat. 131 (1985) 37.

[12] Donnelly, T. A., Fisher, D. G., Murray, R. B. and Swann, C. P., J. Appl. Phys. 53 (1982) 7801 .
[13] Audouard, A., Balanzat, E., Fuchs, G., JousSET, J. C., LESUeur, D. and ThOME, L., Europhys. Lett. 3 (1987) 327.

[14] LindHARD, J., SCHARFF, M. and SCHIOTT, H. E., Mat. Fys. Medd. Dann. Vid. Selsk 33 (1963) 14.

[15] Norgett, N. J., Robinson, M. T. and Torrens, I. M., Nucl. Engin. Des. 33 (1975) 50.

[16] Audouard, A., Balogh, J., Dural, J. and JousSET, J. C., J. Non Cryst. Sol. 50 (1982) 71.

[17] Moser, P., Hautojarvi, P., Yli-Kauppila, J. and CORBEL, C., Radiat. Eff. 62 (1982) 153. 